\title{
Massive Paralysing Rhabdomyoma in a Cameroonian Adolescent: in-between Dejerine-Klumpke, Pancoast-Tobias and Claude-Bernard Horner Syndromes
}

\author{
Georges Pius Kamsu Moyo, Paul Olivier Koki Ndombo \\ Faculty of Medicine and Biomedical Sciences, The University of Yaoundé I, Yaoundé, Cameroon
}

*Corresponding Author: Georges Pius Kamsu Moyo, Faculty of Medicine and Biomedical Sciences, The University of Yaoundé I, Yaoundé, Cameroon, E-mail: kamsuzicfried@yahoo.fr

\begin{abstract}
Rhabdomyoma is a benign tumor of striated muscles. It is most frequently of cephalic and cervical localisation though its occurrence in other body parts such as the thorax remain possible. The clinical presentation of rhabdomyoma is related to the tumor's mass effect which may impact other organs' functions, as it is the case with the upper limbs when the brachial plexus is affected. The management is mainly by surgical resection, which may be total or sub-total as the case may be. Complete recovery is possible, just as recurrence of the tumor, especially after a subtotal resection. Therefore, total excision of the tumor is recommended as much as possible. We present and discuss base on literature review the case of a 13-yearsold female Cameroonian adolescent who presented with a left upper limb numbness and functional impotence evolving for two weeks. This was associated with a painful left cervico-thoracic tumefaction of spontaneous onset, progressing over a period of seven months without fever. Complementary exams permitted to conclude as massive paralysing cervico-thoracic left paraspinal rhabdomyoma, based on CT-scan and pathological exams. The patient was treated by surgical resection through myomectomy. The evolution was favorable, with recovery from limb paresis, numbness and dysesthesia after three months of management. In conclusion, rhabdomyoma may give rise to massive muscle tumors producing compressive effects on nerves with corresponding impairments. Clinical assessment, aided by radiological and pathological exams are necessary for accurate diagnosis. The treatment is mainly surgical and preferably by total tumor excision. Complete recovery is possible and may be accelerated by physiotherapy, but regular follow-up is necessary to check for recurrences.
\end{abstract}

Keywords: Rhabdomyoma, benign tumour, brachial plexus.

\section{BACKGROUND}

The term "Rhabdomyoma" was first introduced by Zenker in 1864 to indicate a benign tumor of skeletal muscle cells with varying degree of differentiation and maturity [1]. Over the years, further research enabled improvements in the definition of rhabdomyoma, as a rare benign tumor of striated muscles affecting the myocardium and skeletal muscles [2]. From an anatomical stand point, cardiac rhabdomyoma which is more common, occurring almost exclusively among the pediatric population and often associated with phakomatosis, may be differentiated from the less prevalent extra cardiac tumors [2, 3]. Extra cardiac rhabdomyoma affects most often, in close to $77 \%$ of cases, body parts such as the cephalic and cervical regions, the digestive system and occasionally the limbs, while only $14 \%$ occur in the genitalia $[4,5]$. Rhabdomyoma of the head and neck originate from the branchial musculature of the $3^{\text {rd }}$ and $4^{\text {th }}$ branchial arches [6]. From a histological point of view, rhabdomyomas may be subdivided into three main subtypes which are the adult, fetal and genital subtypes [7]. Fetal rhabdomyoma may further be subdivided into the classic immature subtype, and the intermediate histological subtype which is characterized by more prominent rhabdomyoblastic maturation [8]. Nevertheless, a number of tumors overlap between these two major subtypes [8]. From a cytological stand point, most rhabdomyomas comprise polygonal frequently vacuolated glycogen containing cells, with fine granular deeply acidophilic cytoplasm, resembling myofibril [9]. All forms of rhabdomyoma may occur in children as well as in adults without 
Massive Paralysing Rhabdomyoma in a Cameroonian Adolescent: in-between Dejerine-Klumpke, Pancoast-Tobias and Claude-Bernard Horner Syndromes

discrimination of sex. The main clinical impact due to rhabdomyomas, regardless of their histological type and their anatomical localisation is associated with a "compressive effect". This is usually progressive and may lead to functional impairments as the tumor increases in size [10, 11]. The treatment aims at decompressing by reducing or removing the excess muscle tissue so as to restore or preserve the neurologic functions. The main challenge for surgeons is choosing between subtotal resection with possible risk of recurrences or total excision which bears less risks, while taking into account the patient's age and the natural history of the tumor $[10,11]$. Repeated clinical and radiological assessments are however required for monitoring after the intervention $[10,11]$.

\section{CASE Summary}

This is the case of a 13-years-old female adolescent, who presented with a left upper limb numbness and functional impotence evolving for two weeks, associated with a painful left cervico-thoracic tumefaction of spontaneous onset, progressing over a period of seven months without fever.

On physical examination, the patient's general state was conserved, the vital and anthropometric parameters were normal for the child's age. Palpebral ptosis, miosis and enophthalmos of the left eye were noted. A left cervico-thoracic paraspinal tumoral mass extending from the spinal levels C1-T4 was equally noted, giving the appearance of a gibbous hump with a pseudo scoliosis. The overlying skin was normal, the mass was firm, tender, mobile over the underlying tissues, well delimitated and dull, without murmurs on auscultation. There was ptosis and slight relative atrophy of the left shoulder and the arm. Dysesthesia and paresis were noted as well, all over the said limb, extending from the shoulder to the fingers. There were no supraclavicular or axillar lymphadenopathy and various pulses were felt. The rest of the physical examination was normal.

The paraclinical exams comprised a cervicothoracic Computed Tomography (CT-scan) which showed a well circumscribed left cervicodorsal muscular mass suggestive of a benign tumor measuring $88 \times 71 \times 95 \mathrm{~mm}$ and a slight ipsilateral compressive distortion of the various thoracic mediastina. The Electromyogram (EMG) of the left upper limb showed a reduced neuromuscular activity in favor of paresis. A biopsy of the mass was done, with pathological analyses revealing well differentiated, hypertrophic and hyperplasic striated muscle cells without cytonuclear atypia. This comforted the diagnosis of a massive benign striated muscle tumor known as rhabdomyoma. All other complementary exams were without peculiarities.

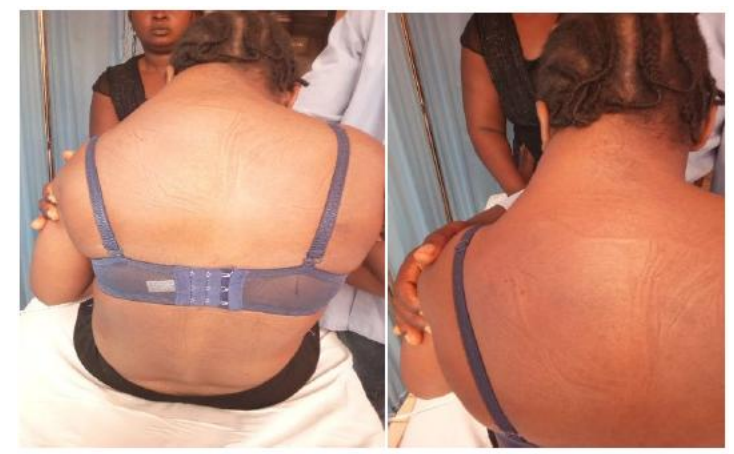

Figure 1. A dorsal view of the cervico-thoracic mass



Figure 2. CT-Scan showing sections across the mass

The surgical resection of the excess muscle mass was performed by myomectomy under general anesthesia, with respect of adjacent tissues. After the healing of the postoperative wounds, the patient was re-educated by kinesitherapy and physiotherapy which were practiced over a period of two months with favorable evolution and recovery from limb paresis and dysesthesia. Control and checking for recurrence was practiced over a year after surgery with no noted regrowth.

\section{DISCUSSION}

The clinical presentation of our patient was predominated by a painful left paraspinal cervico-thoracic mass producing compressive effects on the ipsilateral brachial plexus. This was in turn responsible for ophthalmological signs, paresis and dysesthesia at all segments of the corresponding limb. This presentation is similar to Dejerine-Klumpke syndrome due to 
Massive Paralysing Rhabdomyoma in a Cameroonian Adolescent: in-between Dejerine-Klumpke, Pancoast-Tobias and Claude-Bernard Horner Syndromes

lesions of C8-T2 branch nerves [12]. However, the paresis affected all the limb segments, from the shoulder to the hand, which is a more common sign in Erb-Duschenne palsy due to C5 and C6 branch nerve lesions [13]. Nevertheless, the main causes of Erb-Duschenne palsy may be more serious brachial plexus trauma than compressive effects [13].On the other hand, Pancoast-Tobias syndrome may present with similar manifestations, but resulting from the compressive effects of an apical lung tumor on the brachial plexus. In both Dejerine-Klumpke and Pancoast-Tobias syndromes, ipsilateral ophthalmological signs including palpebral ptosis, miosis, and enophthalmos constitute the Claude-Bernard Horner's syndrome resulting from injuries to nerve branches of the sympathetic trunk [14].

Though soft tissues' benign tumors may occur more frequently than their malignant counterparts, the rule doesn't seem to work for striated muscle tumors, given that rhabdomyomas represents only $2 \%$ of all skeletal muscle tumors $[15,16,17]$.Our patient had a thoracic extension of the tumoral mass, which is quite exceptional as compared to the usual anatomical localisations which are either cephalic or cervical in more than $90 \%$ of cases $[18,19,20]$. The low prevalence of this tumor could be due to the fact that it may be under diagnosed or misdiagnosed especially by unexperienced pathologists from a first try [6].

The diagnosis of rhabdomyoma may be evoked on the basis of the tumor localisation, the patient's age, clinical information about the manifestations and progress of the tumor, which may be supported by radiological imaging [4].Radiological factors in favor of rhabdomyoma include the circumscription of the mass with respect to adjacent tissues [21]. However, the definite diagnosis may only be confirmed by pathological exams [4]. In the present case, the patient was transferred to a neurosurgical referral centre, where biopsy and later on tumor resection were performed. The diagnosis was communicated to us by phone call and written reports from the pathologist and the surgeon without pictures. However, the absences of cytonuclear atypia, infiltrative growth, mitotic activity and necrosis definitely differentiated the benign tumor from its malignant correlate rhabdomyosarcoma and other resembling differentials such as hamartoma [4, 5, 22-24]. The Malignant transformation of rhabdomyoma remains rare and exceptional [19, 25].

The treatment of rhabdomyoma is exclusively surgical by sub-total resection of the tumor, or by complete excision of the excess muscle mass. This is achieved by myomectomy with a possibility to recover functional faculties [6]. The recovery process may be made easier by physiotherapy and re-education as it was the case with our patient.

\section{CONCLUSiON}

Rhabdomyoma is a benign tumor of striated muscles. The clinical presentation is related to the tumor's mass effect which may impact other organs' function through neurological compressive impairments. The diagnosis may be evoked by considering clinical information, radiological imaging and pathological exams which differentiates them from malignant tumors. The management is mainly by surgical resection, which should be total as much as possible in order to prevent recurrences. The complete recovery from impaired functional faculties may be made easier by physiotherapy.

\section{REFERENCES}

[1] Boedts D, Mestdagh J. Adult rhabdomyoma of larynx. Arch of Otorhinolaryngol 1979; 224:221-229.

[2] Di Sant Agnese PA, Knowles DM. Extra cardiacrhabdomyoma: A clinicopathological study and review of the literature. Cancer1980; 46: 780-789.Ranganathan SC, SonnappaS. Pneumonia and other respiratory infections. PediatrClin North Am $2009 ; 56$ :135e56.

[3] Han Y, Qiu XS, Li QC, Han YC, Lin XY, Zhang QF, Wang J, Wang EH, Li ZL. Epididymis rhabdomyoma: a case report and literature review. Diagn Pathol 2012; 7: 47.

[4] Georg Hauer, MD, Jörg Friesenbichler, MD, $\mathrm{PhD}$, Franz Gollowitsch, MD, Andreas Leithner, MD, Lukas A. Holzer, MD, PhDChisti MJ, Tebruegge M, La Vincente S, Graham SM, Duke T. Fetal Rhabdomyoma of the upper Extremity in a 31-Year Old Patient: a Case Report. Arch Bone Jt Surg. 2019; 7(2): 199-202.

[5] Jin B, Saleh H. Pitfalls in the diagnosis of adult rhabdomyoma by fine needle aspiration: reportof a case and a brief literature review. DiagnCytopathol 2009; 37: 483-486.

[6] Feng Wang, Xueling $\mathrm{Hu}$, Qinying Wang, Shuihong Zhou. Adult rhabdomyoma of larynx: a case report.Int J ClinExp Med 2019;12 (1):1314-1318. 
Massive Paralysing Rhabdomyoma in a Cameroonian Adolescent: in-between Dejerine-Klumpke, Pancoast-Tobias and Claude-Bernard Horner Syndromes

[7] Willis J, Abdul - Karim FW, di Sant'Agnese PA. Extra cardiac rhabdomyomas. Semin DiagnPathol, 1994; 11: 15-25.

[8] Kapadia SB, Meis JM, Frisman DM, Elles GL, Heffner DK. Fetal rhabdomyomas of the head and neck: A clinicopathologic and immunophenotypic study of 24 cases. Hum Pathol 1993; 24: 754-765.

[9] O'shea PA. Myogenic Tumor of Solid Tissue. In Pediatric Soft Tissue Tumors: A Clinical Pathological and Therapeutic. O'shea PA,Coffin CM, Dehner LP, editors. Baltimore William and Wilkins; 1997, 214-253.

[10] Santiago-dieppa D R, Zhou T, Jones K A, et al.Intracranial Rhabdomyoma: Case Report and Review of the Literature. Cureus2016; 8(4): e593. DOI 10.7759/cureus.593.

[11] Van Leeuwen JP, Pruszczynski M, Marres HA, Grotenhuis JA, Cremers CW: Unilateral hearingloss due to a rhabdomyoma in a sixyear-old child. J Laryngol Otol. 1995, 109:1186-89.

[12] Shoja MM, Tubbs RS. "Augusta DejerineKlumpke: the first female neuro anatomist" Clin Anat.2007;20(6):585-7.

[13] Erb-Duschenne and Dejerine-Klumpke palsies information page: National Institute of Neurological Disorders and Stroke (MINDS).

[14] Ropper AH, Brown RH. "14: disorders of ocular movements and pupillary function". In Ropper AH, Brown RH (eds). Adams and Victor's Principles of Neurology $\left(8^{\text {th }} \mathrm{ed}\right)$. New York: Mc Grow-Hill Professional. 2005:22245.

[15] Koutsimpelas D, Weber A, Lippert BM, Mann WJ. Multifocal adult rhabdomyoma of the head and neck: a case report and literature review. AurisNasus Larynx 2008; 35: 313-7.

[16] Carta F, Sionis S, Gerosa C, Puxeddu R. Endoscopic management of adult-type rhabdomyoma of the glottis: case report and review of the literature. Braz J Otorhinolaryngol 2016; 82: 244-247.
[17] Altissimi G, Ralli M, Sementilli G, Fiorentino F, Ciofalo A, Greco A, de Vincentiis M, Corsi A, Cianfrone G. Adult-type rhabdomyoma of the larynx: clinicopathologic study of an uncommon tumor in a rare location. Case Rep Otolaryngol 2017; 2017: 7186768.

[18] Kapadia SB, Meis JM, Frisman DM, Ellis GL, Heffner DK. Fetal rhabdomyoma of the head and neck: aclinicopathologic and immunophenotypic study of 24cases. Hum Pathol. 1993; 24(7):754-65.

[19] Osgood PJ, Damron TA, Rooney MT, Goldschmidt AM, Sullivan TJ. Benign fetal rhabdomyoma of the upperextremity. A case report. Clin OrthopRelat Res. 1998;349 (1):200-4.

[20] Willis J, Abdul-Karim FW, di Sant'Agnese PA. Extra cardiac rhabdomyomas. Semin Diagn Pathol.1994; 11(1):15-25.

[21] Weiss SW, Goldblum JR. Enzinger and Weiss's softtissue tumors. 5th ed. New York: Mosby Elsevier;2008.

[22] Pinho MM, de Carvalho E Castro J, Ramos RG. Adult rhabdomyoma of the larynx. Int Arch Otorhinolaryngol 2013; 17: 415-8.

[23] Dermawan JK, Doxtader E, Chute DJ, Policarpio-Nicolas ML. Cytologic findings of an adult rhabdomyoma in the parapharyngeal space: a report of a case and review of the literature. DiagnCytopathol 2018; 46: 419-424.

[24] Cain RB, Gnagi SH, Jaroszewski DE, Lott DG. Adult laryngeal rhabdomyoma with extralaryngeal extension: surgical excision and reconstruction with aortic homograft. Otolaryngol Head Neck Surg 2014; 150: 501-2.

[25] Kodet R, Fajstavr J, Kabelka Z, Koutecky J, Eckschlager T, Newton WA Jr. Is fetal cellular rhabdomyoma anentity or a differentiated rhabdomyosarcoma? Astudy of patients with rhabdomyoma of the tongueand sarcoma of the tongue enrolled in the inter group rhabdomyosarcoma studies I, II, and III. Cancer. 1991;67(11):2907-13.

Citation: Georges Pius Kamsu Moyo, Paul Olivier Koki Ndombo. Massive Paralysing Rhabdomyoma in a Cameroonian Adolescent: in-between Dejerine-Klumpke, Pancoast-Tobias and Claude-Bernard Horner Syndromes. ARC Journal of Pediatrics.2020; 6(1):19-22. doi:dx.doi.org/ 10.2043 1/2455-5711.0601005.

Copyright: (C) 2020 Authors. This is an open-access article distributed under the terms of the Creative Commons Attribution License, which permits unrestricted use, distribution, and reproduction in any medium, provided the original author and source are credited. 